\title{
Control Method for Electric Fuses with Controllable Fusing
}

\author{
Adrian T. Plesca* \\ Department of Power Engineering, Gheorghe Asachi Technical University of lasi, Romania; \\ matrix_total2000@yahoo.com
}

\begin{abstract}
In order to improve the electric fuse features, a new concept of controllable fusing has been patented. The controllable fusing means the possibility of fuse to operate at certain time moments when an external command is activated. The experimental set up has been built on the basis of a virtual instrument application. Using this instrument, there is the possibility to acquire the current waveform which flows through the fuse and set the current threshold when a command signal is provided in order to blow the fuse on the basis of controllable fusing effect. Actually, there is implemented the time-current characteristic of the new fuse, and depending on the application the moment of circuit interruption can be delayed. It results an adjusted new time-current characteristic for the fuse.
\end{abstract}

Keywords: Electric Fuse, Control Method, Virtual Instrument.

\section{Introduction}

The simplest overcurrent protection device is the fuse, which is used in vast numbers throughout the circuit operating voltage range $415 \mathrm{~V}$ to as high as $66 \mathrm{kV}$. The basic principle involves connecting a fuse directly in series with the protected equipment so that, when a given current is exceeded a metallic fuse element(s) melts and thereby breaks the circuit. In this way, fuses both detect and directly isolate faulted equipment from the network, [1].

The term fuse is used in national and international standards to describe a complete assembly. In its simplest form, this consists of a piece of metal wire connected between two terminals on a suitable support; and at its most complex as a cartridge fuse-link mounted in a carrier and fuse base. Modern cartridge fuse-links contain fusible elements mounted in rigid housings of insulating material. The housings are filled with suitable exothermal and arc-quenching powders, such as silica, and they are sealed by metal endcaps which carry the conducting tags or end connections. The metal parts, other than the fusible elements, are invariably of copper, brass, steel or composites and they must be capable of operating under the exacting thermal, mechanical and electrical conditions which may arise in service. A fuse must be able to carry normal load currents and even transient overloads (and the thermal cycling which accompanies them) for a service life of at least 20 years, without any change of state that might affect its electrical performance. This property of non-deterioration requires that the fusible element be both thermally and chemically compatible with the ambient media. It must also respond thermally to overcurrents by melting and subsequently interrupting its circuits. The melting of an element is followed by a period of arcing during which the electrical energy input can be very high, its magnitude and the duration of arcing being dependent on the protected circuit. Successful fault interruption implies that the arcing is wholly contained within the fuselink and the level at which this can be achieved is

* Corresponding author:

Adrian T. Plesca (matrix_total2000@yahoo.com) 
termed the breaking or rupturing capacity of the fuselink. The operating time of a fuselink varies inversely with the level of an overcurrent and discrimination is obtained in networks by choosing fuses with the necessary time/current characteristics and current ratings, [2-3].

Considerations of fuse component properties are important when designing a fuse to operate and efficiently clear fault currents for particular applications. Therefore, many improvements have been made into the original fuse design in order to extend the low current interruption capability, such as: using of non-traditional fuse element metals, like aluminium or cadmium [4], use of bounded silica sand [5], use of two dissimilar bounded or unbounded metals [6], current limiting and expulsion elements put together inside a single fuse body [7], paralleled combination of high-voltage fuse and $\mathrm{Z}_{\mathrm{n}} \mathrm{O}$ varistors [8-10], hybrid fuse using $\mathrm{SF}_{6}$ or vacuum fuse in series with traditional high current part [11, 12], repetition fuse and self-healing or permanent fuse using high pressure sodium and mercury as fuse elements $[13,14]$.

From the literature survey of the main fuse intelligence adding and innovations, the idea of Muth and Zimmermann by 1938 [15], had come out. Afterwards the same idea was developed, especially on the ignition control system, introducing in the market by 1963 the device called limiter [16]. By 1990 a technical paper has been presenting a new design applying this concept to low voltage DC systems, called Smart Fuse [17]. During the seventies an interesting idea was proposed, related to the availability in a single fuse cutout of a double fuse time-current-characteristics which was obtained by using a current transformer which working zone included the saturated and non-saturated areas, changing the two paths current sharing depending on the overcurrent level, [18-20].

\section{The Concept of Controllable Fusing}

With the aim to improve the fuse features, a new concept of controllable fusing has been patented, [21-22]. The controllable fusing means the possibility of fuse to operate at certain time moments when an external command is activated. The key element of the controllable fusing is an electrode which is placed on the fuselink element, as shown in Figure 1, [23-24].

The electrode E, is made from graphite and is pressed on the copper strip of the fuse element F. The electrode terminal is made from brass in order to allow a good

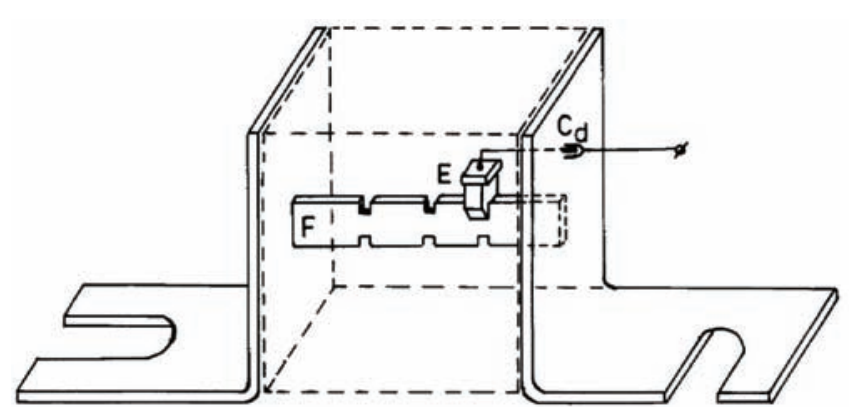

Figure 1. Details of the new fuse cartridge based on the controllable fusing effect.

contact with the supply conductor. With the aim to supply this electrode, a detachable contact $\mathrm{Cd}$, or a plug device is used in the case of more parallel fuselink elements, [25-28].

Thus, when an overcurrent occurs within an electric circuit where a high breaking capacity fuse is mounted to protect a device against overcurrents, especially shortcircuits, some transducers which are sensitive at current value, di/dt, temperature, etc., will provide a command signal for a power switch. This switch will supply with the necessary power the electrode E, Figure 1, which finally will interrupt the fuse element F, through an auxiliary electric arc. Therefore, the fuse will turn off the main electric circuit.

\section{Experimental Tests}

In order to test the new type of high breaking capacity fuse a test circuit has been used as shown in Figure 2, based on a data acquisition board DAQ, programmed using LabVIEW software.

From the diagram of the power circuit used for experimental tests, we can observe the main circuit where the fuse under test SF, Figure 2, is supplied from a high power current source TC. This is an electromagnetic device built on the principle of power transformers with a primary winding made with many turns and small cross-section, and the secondary winding has a few turns but with high cross-section proper for high currents. Thus, the current source is supplied with variable input voltage from the autotransformer ATR and provides high variable output current which flows through the fuse under test SF.

In order to obtain the controllable fusing an auxiliary energy is provided from the auxiliary transformer TA which is supplied by the autotransformer A-ATR. At the moment when we wish to test the fuse, the power electronic switch $\mathrm{K}$, made with two thyristors mounted in antiparallel, which 


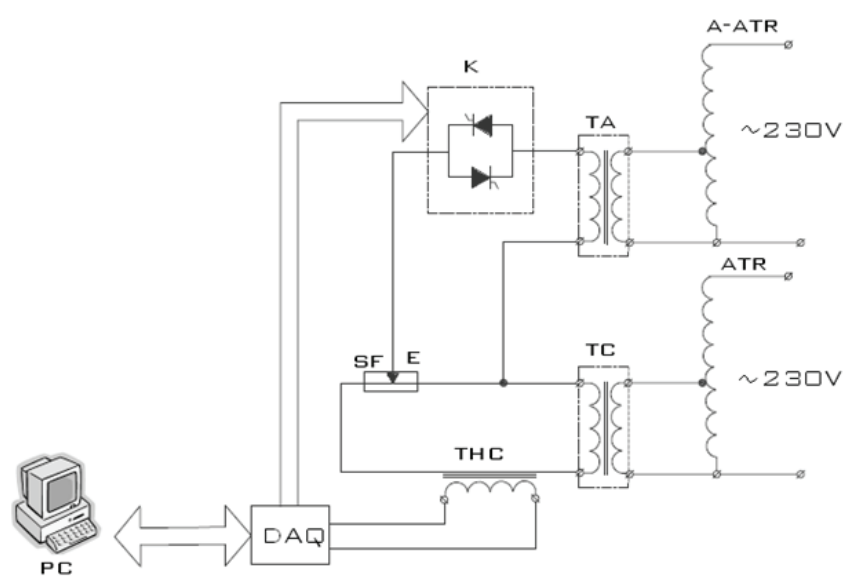

Figure 2. Diagram of the power circuit for experimental tests of the new fuse.

is controlled by the data acquisition board DAQ, will turn on and the supplementary energy from the auxiliary transformer TA, through the electrode E, will blow the fuse SF.

An adequate current transducer THC, type HTA 1000S using the construction principle of Hall effect, allows to record the prospective current.

The experimental tests have been done at different prospective current values. It has been tested high breaking capacity fuses with the rated current of $100 \mathrm{~A}$, a rated voltage of $690 \mathrm{~V}, \mathrm{gG}$ operating class and the supplementary current of the auxiliary source was about 20A. The fuse element is made from copper and has the following overall dimensions: length of $68 \mathrm{~mm}$, width by $18 \mathrm{~mm}$ and thickness of $0.12 \mathrm{~mm}$. Silica sand used in the tests is the same as the industrial one.

Actually, the new fuse using the input data such as current, di/dt, temperature, etc., will process data with data acquisition board DAQ and provide the commands for an efficiently and safety circuit interruption.

Further on, the LabVIEW application's front panels are shown in Figure 3-5. The virtual instrument has been designed on the basis of tabs' principle graphical programming. Thus, the first tab, Figure 3, means the configuration module where the following parameters are specified: number of the device (data acquisition board), number of the analog input and digital output channel, scan rate and the signal limits (high and low) for analog input channel.

The second tab, Figure 4 and 5, includes data processing and on the front panel there are the prescribed limits'button, the waveform of acquired prospective current, the desired time-current characteristic and a digital flag which indicates the status of the digital output channel (green - no digital output signal; red - digital output signal provided).
For normal operating conditions, Figure 4, the acquired current value is under the low limit respect to time-current characteristic, thus the data acquisition board DAQ, will not provide digital output signal and the digital flag status has green colour.

When the prospective current acquired value is over the low limit, then this value is compared with the values of the time-current characteristic and after a certain delay, the data acquisition board DAQ, will provide a digital output signal to turn on the power electronic switch $\mathrm{K}$, and finally the fuse will blow. During this time, the digital flag status has red colour, Figure 5.

The desired time-current characteristic is included as a fitted curve in the virtual instrument programmed with LabVIEW software. For instance, if the desired timecurrent characteristic is the catalogue one, for a $100 \mathrm{~A}$ rated current and $690 \mathrm{~V}$ rated voltage, this characteristic can be fitted by the equation below,

$$
t(i)=\frac{a+c \cdot i^{2}}{1+b \cdot i^{2}+d \cdot i^{4}}
$$

where the parameters $a, b, c$ and $d$ have the following values:

$$
\begin{aligned}
& a=246.75 ; \\
& b=8.534 \cdot 10^{-5} ; \\
& c=1.952 \cdot 10^{-5} ; \\
& d=1.915 \cdot 10^{-9} ;
\end{aligned}
$$

The fitted curve with the above parameters' values have been obtained using a specific fitting software. The comparison between the catalogue characteristic and the fitted one is shown in the figure below, Figure 6 .

Thus, there is the possibility to implement into the virtual instrument made with LabVIEW software, any desired time-current characteristic depending on the application where the fuse is mounted.

Further on, an oscillogram with the recorded arc current and voltage at 550A prospective current for the new type of fuse is shown in Figure 7. It can be noticed an overcurrent of about 1250A during circuit interruption, but there is no overvoltage. The recovery voltage is about $25 \mathrm{~V}$ which is the value provided by the auxiliary transformer. The total breaking time for the fuse is about $30 \mathrm{~ms}$. From datasheets, this total time corresponds to a prospective current of $1100 \mathrm{~A}$, and from the current of $550 \mathrm{~A}$ there is a total breaking time of 3 seconds. Thus, using the controllable fusing, we can anticipate the moment of circuit interruption and decrease the total breaking time for the fuse up to 100 times, in this case. So, there is the possibility to obtain 


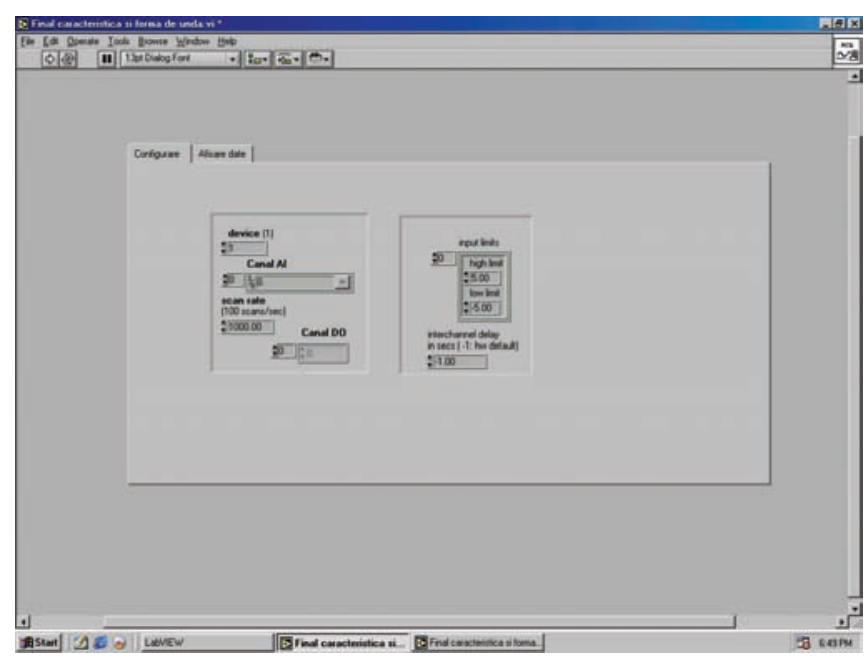

Figure 3. Front Panel of the LabVIEW application: configuration of the data aquisition board parameters.

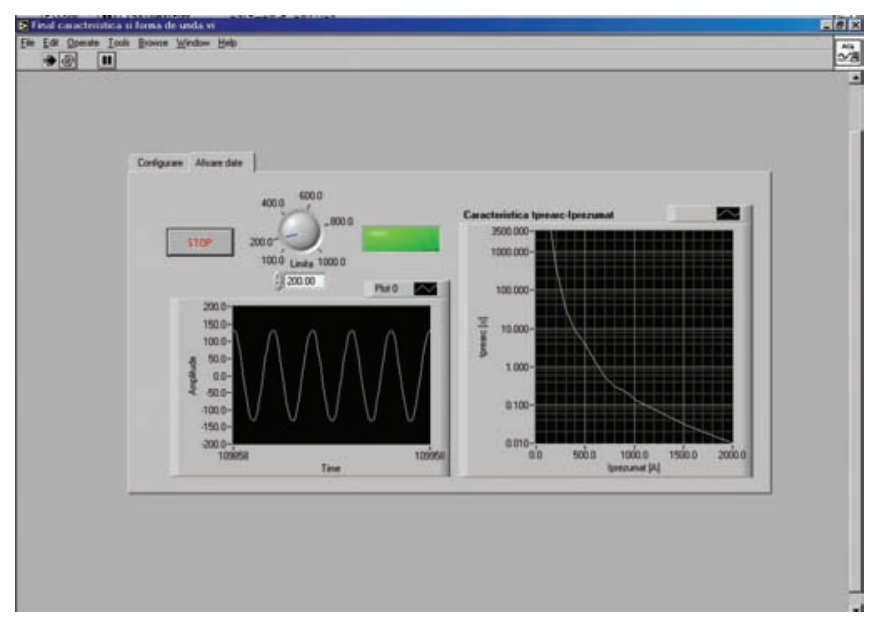

Figure 4. Front Panel of the LabVIEW application: normal operating.

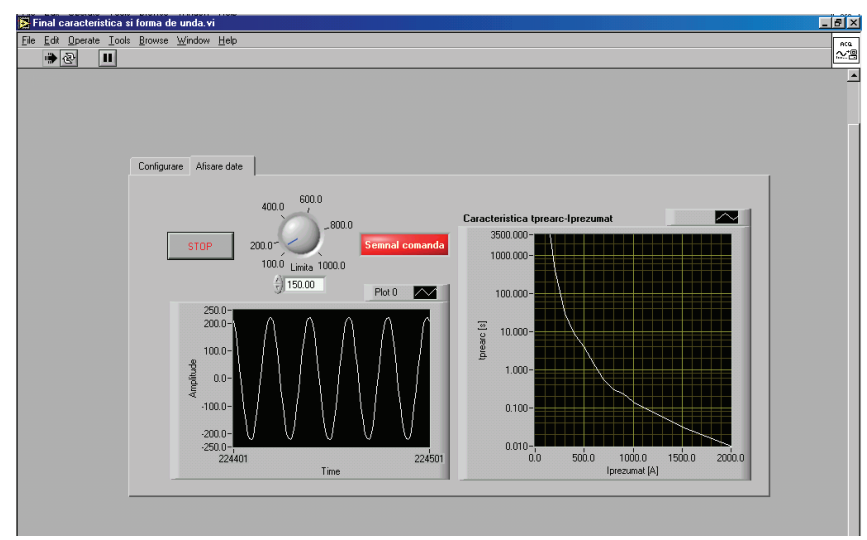

Figure 5. Front Panel of the LabVIEW application: overload.

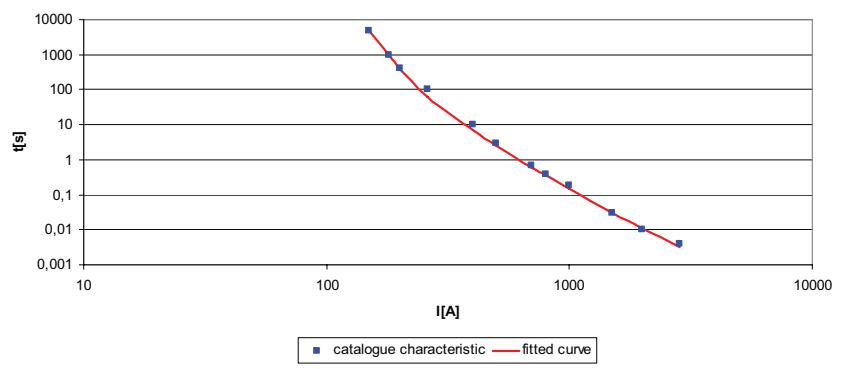

Figure 6. Comparison between catalogue characteristic and the fitted one.

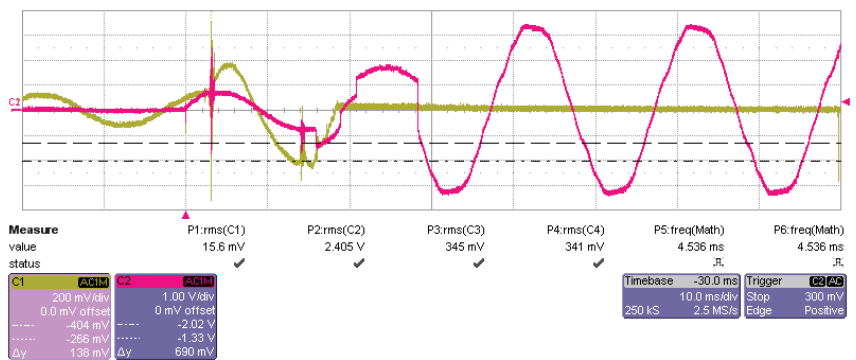

Figure 7. Current and voltage arc in the moment of circuit interruption by the fuse with controllable fusing effect.

adjustable time-current characteristics depending on the type of the device to be protected against overcurrents.

\section{Conclusions}

The theoretical aspects related to the new type of high breaking capacity fuse based on the controllable fusing effect and all the experimental tests outline that there is the possibility to extend the current protection range both to overloads and shortcircuits. Thus, the traditional passive overcurrent protection becomes an active one enhanced with new features such:

- controllable fusing level;

- controllable current-limiting effect;

- adjusted time-current characteristics;

- protection possibilities from overload to shortcircuits;

- protection to direct current sense and power line sense at AC applications;

- protection to di/dt.

Extending the new concept of controllable fusing for the specific applications enables the user of high breaking capacity fuses to choose the right ratings, to evaluate critical load cycles and to identify potential overload capacities for a dynamic grid loading. 
It was shown that the described new fuse has a high potential for a variety of different applications:

- development support;

- identifying user risks;

- evaluating the right rated current.

\section{Acknowledgements}

This work was supported by CNCSIS - UEFISCDI, project number 610 PNII - CAPACITATI, 2013.

\section{References}

1. Wright A, and Newbery P G (2004). Electric Fuses, Chapter 3, London: IEE.

2. Nairne E (1774). Electrical Experiments by Mr. Edward Nairne, of London, Mathematical instrument-maker, made with a machine of his own workmanship, a description of which is prefixed, philosophical transactions, vol 64, 79-89.

3. McEwan P, and Nairne E (1996). FRS - Discoverer of the electric fuse?, Perspektywy Rozwoju Technik Przerywania Pradu Gdansk, vol 2, 24-31.

4. Metcalf A (1939). A new fuse phenomenon, Beama Journal, vol 44, 109-112 and 151-152.

5. Westrom A, Crooks W R et al. (1981). Current limiting fuses a comparative evaluation, $9^{\text {th }}$ IEEE Power Engineering Society, vol PER-2(7), 25-26.

6. Leach J G (1985). New application flexibility for mediumvoltage current-limiting fuses, IEEE Transaction on Industry Applications, vol IA21(4), 1075-1080.

7. Narancic V, Braunovic M et al. (1979). The composite fuse a new technology for current limiting fuses, $7^{\text {th }}$ IEEE Power Engineering Society Transmission and Distribution Conference and Exposition, 462-470.

8. Gómez J, Tourn D et al. (1991). Investigation of the prearcing behavior of dissimilar uniform double element CAD techniques, Fourth International Conference on Electric Fuses and their Applications (Nottingham), 65-70.

9. Rosen P (1983). Full-range fusing - a new concept in system protection, Electrical Review, vol 213, 33-41.

10. Miura H, Takaoka N et al. (1979). New dual-element current limiting power fuse with full protection capability against any fault current, IEEE Transaction on Power Apparatus and Systems, vol PAS-98, 1885-1894.
11. Wolny A, Stokes A D et al. (1994). High-voltage behavior with varistor commutation, IEE Proceedings Generation, Transmission and Distribution, vol(1)141, 3337-3345.

12. Bucher $T$ (1982). Encapsulated current limiting fuses: grounded-front design, IEEE Transaction on Power Apparatus and Systems, vol PAS-101(7), 1975-1978.

13. Itoh $\mathrm{T}$ (1973). Design considerations on the ppf for a control center, IEEE Transaction on Power Apparatus and Systems, vol PAS-92(4), 1292-1297.

14. Gundlach $H$ (1977). A self-restoring current-limiting device, $3^{\text {rd }}$ International Symposium on Switching Arc Phenomena (Poland), 287-292.

15. Muth H, Zimmermann $K$ et al. (1938). Sicherungen im Maschennetzbetrieb, ETZ, vol 59, 1257-1261.

16. Brukner $P$ (1958). A new type of switching device with extremely short breaking time, ETZ, vol 33, 1137-1146

17. Martin D (1990). Smart fuses enter with a small bang, Electrical Review, vol 7.

18. Aubrey D (1974). New $11 \mathrm{kV}$ expulsion fuses for overhead lines, Electrical Times, 50-56.

19. Barrow D R, Howe A F et al. (1991). The chemistry of electric fuse arcing, IEE Proceedings A, Science Measurement and Technology, vol 138(1), 83-88.

20. Agarwal M S, Stokes A D et al. (1987). Pre-arcing behaviour of open fuse wire, Journal of Physics D: Applied Physics, vol 20, No. 10, 1237-1242.

21. Plesca A (2002). Protection device for power semiconductors, Patent RO 117882.

22. Plesca A (2002). Modular fuse for protection of installations with semiconductors, Patent RO 117953.

23. Plesca A (2005). Overcurrents protection device, Patent RO 119396.

24. Plesca A (2005). Special cartridge for HRC fuses, Patent RO 120107.

25. Plesca A (2005). Special fast fuse for power semiconductors protection, Patent RO 120108.

26. Plesca A, and Leonte P (2006). Special fuse for power rectifier, Patent RO 120436.

27. Chiriac G (2012). Thermal analysis of fuses with variable cross-section fuselinks, Electric Power Systems Research, vol 92, 73- 80 .

28. Cantemir L, Nituca C et al. (2011). Unconventional current collection from a contact line for electric traction vehicles, International Conference on Pantograph Catenary Interaction Framework for Intelligent Control, Amiens, France. 